\section{IJ§ER}

ISSN: 2149-5939
International Journal of Social Sciences and Education Research

Online, http://dergipark.gov.tr/ijsser

Volume: 2(2), 2016

\title{
Gösterilebilir şiddetin gerçekliği
}

\author{
The reality of demonstrable violence
}

Elif Ergün ${ }^{1}$

Received Date: 22 / $10 / 2015$

Accepted Date: 29 / $01 / 2016$

\begin{abstract}
$\ddot{O} z$
İşittiğimiz, doğruluğunun ispatlanmasını istediğimiz şeyin fotoğrafinı görmek isteriz. Kayıt altına alınmış olmak önemlidir. Fotoğrafin çarpıtılma ihtimali yüksek olsa bile biz o fotoğrafi görmek isteriz. Bazen fotoğraflar yazılı olarak iletilen şeylerin doğruluğunun ispatı görevini de görürler. Belgesel nitelikteki fotoğrafa yönelik eleştiri söz konusu olduğunda akla gelen ilk isim Sontag'dır. Fotoğrafin belgeselliğini sorgulayan Sontag için gerçeklik ve görüntü arasında artık kapanmaz bir yarık açıldı. Onun, ısrarla fotoğraflara eşlik eden bir alt yazı olmasa onlar hakkında yorumun eksik çoğu zamanda hatalı olacağını belirtmesinin ardında da bu görüş vardır. Fotoğraf ancak bir açıklama ile beraber belge niteliği kazanacaktır. Bu uygulama Sontag'a göre oldukça yaygındır. Çünkü fotoğrafin bir de kendisinin bir bilgi nesnesine dönüşme, bilgiyi çoğaltma işlevi vardır. Sontag'ın fotoğrafin belgesel olma özelliğine dair hiç değilse temkinli olmasının ardında birkaç gerekçe vardır. Bunlardan ilki fotoğrafin gerçeklik fikrini değişime uğratmış olmasıdır. Öyle ki ancak bir alt yazı ile biz aslında fotoğrafi bir gerçeklik alanına yerleştirebiliriz. Bir diğer gerekçe aslında çağdaş bir klişe olan fotoğrafin bizi hissizleştirdiği fikridir. Öyle ki korkunç imgelere sürekli, durmadan maruz kalan bireyler bir süre sonra bu görüntünün etkisine kapılmazlar bile. Aynı klişeyi sinemada da görürüz. Çăgdaş yönetmenler bunu fazlasıyla kullanmışlardır. Sontag'ın diğer bir gerekçesi savaşların bitimsiz, sonu olmayan ve önlenemeyecek olması gerçeğidir. Ona göre bu fotoğraflar başlı başına bir retorik türüdür ve bir olguyu tekrarlayarak çoğaltılırlar. Onu basitleştirirler. Oysa aynı fotoğraflar için Sontag'dan farklı olarak Linfield, fotoğrafların bizlere insan olanı anlamadaki mecburi başarısızlığımızı öğrettiğini söyler. Bu anlamda fotoğraf belge niteliği olmasının yanı sira siyasal bir bilinç de yaratır. Sontag, fotoğrafin üzerimizde bir etki bıraktığını kabul etmekle beraber bunun geçiciliğine vurgu yapmıştı. Ona göre fotoğrafin yarattı̆̆ "şok" etkisiydi ve bu etki de bize yorumlama imkânı sunmamaktaydl. Bir fotoğraf ancak altındaki açılklama metni ile açıklık kazanıyordu. Dolayısıyla Sontag için fotoğrafin politik ve etik anlamı kuşkuluydu, tanıklığı tartışılmaydı. Oysaki Butler, fotoğrafin özellikle savaş ve şiddet fotoğraflarının algılanabilir bir gerçeklik sunduğunu kabul eder ve Sontag'a itiraz eder. Ona göre fotoğraflar anlam dünyamızı sarsabilir, tanıklı edebilir, savaş suçlarının kanıtlanmasında delil olarak kullanılabilir. Butler'ın Sontag'ın yazılarına getirdiği eleştiri bu manada haklıdır. Dolayısıyla fotoğrafin kendi başına bir yorum sunmadı̆̆ lerle tamamlamak gerektiği yolundaki yorumu kabul etmek mümkün değildir. Fotoğrafin kendi gerçekliğinde kamuoyunu etkileme en azından merak uyandırma işlevi malumdur. Üzerinde türlü çeşitli spekülasyon yapılan olayın açı̆̆a çıkan fotoğrafi Butler'ın da vurguladı̆̆ı gibi yazılı açıklamaya bile gerek bırakmayabilir. Bu bildiri, Sontag'ın fotoğrafa dair eleştirisinden hareketle bu tür şiddet fotoğraflarının anlamına dair bir kritik etme girişimidir. Bir fotoğraf bize ne söyler? Fotoğrafin kurgusal dünyası gerçekliği ne kadar yansitabilir? Kurmaca ile gerçeklik arasındaki ilişkinin sınırını fotoğraf değiştirebilir mi? gibi sorular çerçevesinde gösterilebilirlik soru konusu edilmiştir.
\end{abstract}

Anahtar sözcükler: Fotoğraf, Bakış, Şiddet, Savaş, Sontag.

\begin{abstract}
When there is a critique about the photograph which is documentary, Sontag is the first name that comes to mind. For Sontag a gap is opened - who questioned the photograph is a documentary or not-between reality and image, it is no longer closes. According to her photograph just will gain documentary qualification with a description. There are several reasons why Sontag is -to say the least-cautious about photograph's property of being documentary. The first of these is that photograph changed the idea of reality. Such that we can barely place the photograph just with a subtitle in fieald of reality. The idea that photograph makes us insensitive which is actually a contemporary cliche is another reason. In fact, the people who are continuously exposed to horrible images, a
\end{abstract}

\footnotetext{
${ }^{1}$ Assist. Prof. Dr., Sakarya University, Faculty of Science and Letters, Philosophy Department, SAKARYA/TURKEY,
} eergun@sakarya.edu.tr 
Ergün, E. (2016). Gösterilebilir şiddetin gerçekliği. International Journal of Social Sciences and Education Research, 2 (2), 364-373.

little while later won't be affected by them. We see the same cliche in the cinema. Modern directors used this a lot. Another argument of Sontag is the reality that wars are endless and unavoidable. According to him photograph is kind of a rhetoric on its own and it is reproduced by recursion of a phenomenon. It simplifies the phenomenon. However, unlike Sontag, Linfield says that photographs show us our inevitable failure of understanding what is human. In this sense, photograph creates a political awareness besides its documentary characteristic. Sontag, acknowledged that the photo had made an impression above us with its emphasis on temporariness. According to her, the photo caused "shock" effect and also this effect was not give us opportunity for interpretation. A photo has barely clarified with a description text under it. Thereby the photo's political and ethical meaning was skeptical, its witness was eristic for Sontag. Whereas Butler object to Sontag and acknowledged that the photo -especially war and violence's photos- gives us opportunity to a perceptible reality. According to her, photos could change our world, could be witness and could use to prove war crimes. Butler's critiques on Sontag's writing is right in this sense. This paper is an attempt to critical based on the critics of Sontag's about photo and about these kind of photo's meaning. The demonstrability has semtinized within the frame of such questions "What does a photo tell us? How could the photo's fictional world reflect the reality? Could a photo change boundaries of the relation between fiction and reality?"

Keywords: Photo, Wiev, Violence, War, Sontag

\section{Giriș}

Benim ve sizin acınızın bir başkasının gurur ve neşe kaynă̆ olduğu bir dünyaya güvenmek kolay değildir. Acımasız Aydınlık, Linfield.

Modern çă̆ın simgeleri denildiğinde ilk akla gelenlerden biri de fotoğraftır. Resim sanatı ile karşılaştırılması, kopuşu, kendi başına bir sanat sayılıp sayılamayacağı gibi çatışmalara ve gerilimlere yol açan fotoğrafın aynı zamanda belgesel bir niteliği de vardır. Bu nitelik de en az diğerleri kadar güncelliğini koruyan bir tartışmadır. Barthes’ın fotoğraf “özneyi nesne, hatta bir müze nesnesi haline dönüştürmüştür” (Barthes, 2011.25) yargısı fotoğrafın "belge” sayılıp sayılmamasına dair yapılan tartışmaların kapsamına dâhil edilebilir. Elbette ki bu tartışmalar moderndir ve Linfield'ın dediği gibi "fotoğrafın su yüzüne çıkardığı kaygılar, modernitenin ortaya çıkardığı kaygılardır" (Linfield, 2013:27). Bunu dile getiren yalnızca Linfield değil kuşkusuz. Ondan çok önce, neredeyse adı modernite ile birlikte anılan Benjamin de fotoğrafın ve fotoğrafik metotların, sinsi bir şekilde kapitalist sanayinin kriziyle bağlantılı olabileceği (Benjamin, 2014:7) uyarısında bulunmuştur.

Sontag'a göre fotoğraf, özünde orta sınıfa özgü olup, hümanizm denen hem şevkle hem de hoşgörüyle hem merakla hem de kayıtsızlıkla takınılan tutumun bir aracıydı-ve bu tutuma göre, en büyüleyici dekor yoksul kenar mahallelerdi (Sontag,2008:68). Fotoğraf, zamanla orta sınıfa özgü bir etkinlik işlevini geride bırakıp sanat haline gelmiştir. Özellikle toplumsal olayların yaşandığı zamanlarda önemi bir hayli artmıştır. Bugün artık fotoğraf tarihte hiç olmadığı kadar yaygınlaştı. Bununla beraber gün geçtikçe daha fazla görüntü şokuna uğruyoruz. Ancak bu şok deneyimi bu yaygınlaşmayla beraber etkisini ne ölçüde sürdürebiliyor bunu kestirmek bir hayli güçleşti. Sontag'ın ifadesiyle "biz insanlar korkunca ateş eder, nostalji duyunca fotoğraf çekeriz" (Sontag,2008:18).

\section{Literatür}

Fotoğraf modern bir gösterge ise bu aynı zamanda onun o dünyanın diğer nitelikleriyle olan bağının da açığa çıkarılması gerektiği anlamına gelir. Diğer bir deyişle modern ile hayatın içine 
Ergün, E. (2016). The reality of demonstrable violence. International Journal of Social Sciences and Education Research, 2 (2), 364-373.

dâhil edilen; hız, değişim, uçuculuk, kayboluş, hafiza, unutuşla fotoğraf arasında bağ vardır. Berger, fotoğrafın kayboluşa karşı bir meydan okuma (Berger, 2014:159), olay ile fotoğrafçının karşılaştığının bir kanıtı (Berger, 2014:159) olduğunu söyler. Bu bağlamda hatırlama/hatırlatma aynı zamanda bir belgeleme kanıtlama demektir de. İkinci özellik olan olay ile fotoğrafçının karşılaşmasında ise belgeleme konusu ilkinden çok daha içseldir. O zaten bu yüzden de bir belgedir.

Sontag'a göre fotoğraf bize yeni bir görsel şifre öğretmek suretiyle, bakılmaya değer olan şeyler ile kendimizde olanları gözlemleme hakkını bulduğumuz şeylere ilişkin görüşlerimizi değiştirip genişletir. Bir dilbilgisi ve -daha da önemlisi- bir görme etiği oluşturur. Ayrıca fotoğraf çekme girişiminin en görkemli sonucu, bize bütün dünyayı -bir görüntüler antolojisi şeklinde-kafamızın içine sığdırabileceğimiz duygusunu kazandırmasıdır (Sontag, 2008:1-2). Fotoğrafların bu üç özelliğinin kaçınılmaz sonucu ise onların birer kanıt sunduğu gerçeğidir. İşittiğimiz, doğruluğunun ispatlanmasını istediğimiz şeyin fotoğrafını görmek isteriz. Kayıt altına alınmış olmak önemlidir. Fotoğrafın çarpıtılma ihtimali yüksek olsa bile biz o fotoğrafı görmek isteriz. Bazen fotoğraflar yazılı olarak iletilen şeylerin doğruluğunun ispatı görevini de görürler. Buna sayısız örnek verilebilir ama örneğin Guantanamo hakkında ilk elde kulağa gelen bilgiler, mahkûmların bir şekilde dış dünyaya ulaştırdığı günlüklerde yazılı olanların sonradan fotoğraflar aracılığıyla doğrulandığı görülmüştür. Bu günlüklerin en ünlüsü $\mathrm{M}$. Slahi'ye ait olandır. Slahi'nin günlükleri altı yıldan uzun süre el yazmasının kamuoyuna açıklanması için mücadele eden gönüllü avukatları sayesinde sansürlü de olsa kitaplaştıııldı. Guantanamo fotoğraflarının hemen ardından yayınlanan günlükler, "tek isteğim hikayemin anlaşılması" (Slahi, 2015:25) diyen yalnızca Slahi'ye değil orada olup biten hukuk dışı uygulamalara dair de bir kanıt niteliğindedir. Kamuoyunda büyük yankı uyandıran fotoğraflar başka bir kaynak ile doğrulanmıştır.

Fotoğrafla birlikte birçok şey değişti. Bundan sonra insanın görünüşü değişti. Berger'in ifadesiyle "görünen nesneler başka bir anlama gelmeye başladı" (Berger, 1986:18). Ancak en büyük değişim gerçeklik fikrinde yaşandı. Öyle ki, Sontag'a göre fotoğraf şeylerin bizim gözümüze nasıl görüneceğinin normu haline geldi (Sontag, 2008:106). Dolayısıyla fotoğrafın belgeselliğini sorgulayan Sontag için gerçeklik ve görüntü arasında artık kapanmaz bir yarık açıldı. Onun, 1srarla fotoğraflara eşlik eden bir alt yazı olmasa onlar hakkında yorumun eksik çoğu zamanda hatalı olacağını belirtmesinin ardında da bu görüş vardır. Fotoğraf ancak bir açıklama ile beraber belge niteliği kazanacaktır. Bu uygulama Sontag'a göre oldukça yaygındır. Çünkü fotoğrafın bir de kendisinin bir bilgi nesnesine dönüşme, bilgiyi çoğaltma işlevi vardır. Fotoğraf, aile albümlerine kabaca kronolojik bir sırayla yerleştirilmiş şipşak fotoğraflardan tutun, hava tahmini, astronomi, mikrobiyoloji, jeoloji, polisin faaliyetleri, tıp eğitimi ve teşhis, askeri keşif ve sanat tarihi gibi alanlarda kullanılması için gerekli daimi arşivlere ve titiz dosyalara kadar uzanan, sınıflandırma ve saklama şemalarına uygun bir sistemdir. Fotoğraflar, sıradan deneyimlere ait malzemeleri (insanlar, şeyler, olaylar ya da doğal bakışımızla -farklı bir şekilde, genellikle ise öylesine baktığımızda- her ne görüyorsak) yeniden tanımlamaktan daha öte bir işlev görür ve kendimizin hiçbir zaman göremeyeceğimiz muazzam miktardaki malzemeyi çoğaltırlar (Sontag, 2008:184). Enformasyona ait bir sahada bol miktarda yığılan malzemenin sınıflandırılması ancak bu açıklamalar sayesinde mümkün olacaktır. Sınıflandırma ve açıklama olmadan gerçeklikten değil yalnızca görünüşten bahsedilebilir. Bu ise yapılacak yorumun doğruluğunu tehlikeye uğratacaktır.

Sontag'ın fotoğrafın belgesel olma özelliğine dair hiç değilse temkinli olmasının ardında birkaç gerekçe vardır. Bunlardan ilki yukarıda değinilen fotoğrafın gerçeklik fikrini değişime uğrat- 
Ergün, E. (2016). Gösterilebilir şiddetin gerçekliği. International Journal of Social Sciences and Education Research, 2 (2), 364-373.

mış olmasıdır. Öyle ki ancak bir alt yazı ile biz aslında fotoğrafı bir gerçeklik alanına yerleștirebiliriz. Bir diğer gerekçe aslında çağdaş bir klişe olan fotoğrafın bizi hissizleştirdiği fikridir. Öyle ki korkunç imgelere sürekli, durmadan maruz kalan bireyler bir süre sonra bu görüntünün etkisine kapılmazlar bile. Aynı klişeyi sinemada da görürüz. Çağdaş yönetmenler bunu fazlasıyla kullanmışlardır. Örneğin Haneke filmlerinde arka fonda açılmış televizyonda savaş ve şiddet görüntüleri akarken bir yandan da aile akşam yemeğini huzur içerisinde yemeğe devam eder. Acının ya da şiddetin enformasyonun, o hızlı akışın figürü olması elbette ki bu görüntülerin etkisini azaltır. Korkunç imgeler sağanağı hissizleştirir ancak yine de belge olma niteliğini yitirmezler.

Sontag'ın diğer bir gerekçesi savaşların bitimsiz, sonu olmayan ve önlenemeyecek olması gerçeğidir. Sontag haklı olarak bize şunu sorar: "eğer böyleyse yani savaş hiç bitmeyecekse savaş kurbanlarının fotoğraflarını nasıl konumlandıracağız?" (Sontag, 2004:4). Ona göre bu fotoğraflar başlı başına bir retorik türüdür ve bir olguyu tekrarlayarak çoğaltılırlar. Onu basitleştirirler. Ayrıca, sarsıcıdırlar ve bir konsensüs olduğu yanılsaması yaratırlar (Sontag, 2004:4). Oysa aynı fotoğraflar için Sontag' dan farklı olarak Linfield, fotoğrafların bizlere insan olanı anlamadaki mecburi başarısızlığımızı öğrettiğini söyler. Ona göre fotoğraf bizleri 1stırap deneyimlerine diğer tüm sanat ve gazetecilik biçimlerinden daha çok yakınlaştırır (Linfield, 2013:11). Fiziksel acı söz konusu olduğunda ne edebiyat ne de resim aynı gerçekliği fotoğrafın aktardığı biçimiyle aktaramaz. Fotoğrafta gösterilenle başka türlü bir ilişki kurulur. Edebiyat ya da resim söz konusu olduğunda onu anlamlandırma noktasında biraz daha özgürsünüzdür. Oysa savaş ya da katliam fotoğrafları çoğunlukla yüzleşmek istemediğimiz, vahşi yönümüzü hatırlatırlar.

Sontag, fotoğraflar kadar fotoğraflara bakan kişiler sebebiyle de fotoğrafın gerçekliğine temkinli yaklaşır. Ona göre aynı fotoğrafa bakan kişiler benzer tepkiyi vermezler, kişiler kimlikleri uyarınca onu görürler. Örneğin hakkın ve haklılığın bir tarafta, baskı ve adaletsizliğin diğer tarafta yer aldığına ve kavganın sürdürülmesi gerektiğine inananlar açısından önemli olan, tam da kimin, kim tarafından öldürüldüğüdür. Bir İsrailli Yahudi’nin gözünde, Kudüs'ün merkezindeki Sbarro pizzacısına düzenlenen saldırıda paramparça olan bir çocuğun fotoğrafı, öncelikle, Filistinli bir intihar bombacısı tarafından öldürülen bir Yahudi çocuğun fotoğrafıdır. Bir Filistinlinin gözündeyse, Gazze'de devriye gezen bir tankın ezerek paramparça ettiği bir çocuğun fotoğrafi, öncelikle, İsrail ordusunun bir zırhlı aracı tarafından öldürülen bir Filistinli çocuğun fotoğrafıdır. Militanın bakış açısıyla, kimlik her şeydir (Sontag, 2004:9). Hatta bu insanlar için fotoğraflar düşmana duyulan kini koyulaştırmaya yarayabilir. Elbette ki fotoğrafların haberlerde verilme şekliyle de gerçekliği üzerinde hiç değilse bir algı oluşturduğu eklenebilir. Bakan kişi kadar bakılan fotoğraf da bambaşka bir hale bürünür. Özellikle bu militan bakışın Sontag'ın ifade ettiği gibi kendisinin ait olduğu tarafın işlediği vahşetlerin fotoğraflarla kanıtlanması durumunda yapıştırdığı standart cevap, söz konusu resimlerin kesinlikle sahte olduğu, bu tür vahşetlerin yaşanmadığı, ya da, evet, bu tür vahşete tanık olunduğu, fakat bu vahşeti işleyenlerin öteki taraf olduğu şeklindedir (Sontag, 2004:10). Sosyal medyanın yaygın kullanımında bu tür haberlere oldukça sık rastlanır. Söz konusu durumda aidiyetler ön plana çıkartılır. Eylemin ne olduğundan ziyade eyleyen öznelere göre bir gerçeklik, alg1 oluşturulur. Eylemin özneleri geçmişte de benzer katliamlara sebebiyet vermişlerse bu algıyı oluşturmak daha da kolaylaşır. Paramparça olan bedene öncelikle "kim?" sorusuna verilecek cevaba göre bir tavır takınılır.

Sontag, yukarıda sayılan sebeplere bağlı olarak fotoğrafın gerçeklikle olan bağını sorunlu bulsa da şu kabulü ortaya koyar: fotoğrafların başkalarının acısına bakmak açısından sunduğu sayısız fırsatın çok çeşitli yararları vardır. Bir vahşeti resimleyen görüntüler kolaylıkla birbirine zıt tepkiler uyandırabilir. Bu bir barış çağrısı olabilir. Veya bir öç çığlığı olabilir. Ya da sadece, 
Ergün, E. (2016). The reality of demonstrable violence. International Journal of Social Sciences and Education Research, 2 (2), 364-373.

fotoğrafik bilgilerin sürekli belleğe atılıp üst üste yığılması sonucunda, yaşanan korkunç şeylere dair bir kafa karışıklığı yaratabilir (Sontag, 2004:12). Fotoğraflar, onlara bakanların niyetlerine bağlı olarak birbirinden farklı tepkilere sebep olabilirler. Bu durumda katliam ya da vahşet belgesi niteliğinde olan fotoğraflar hukuksal alanda olumlu gelişmelere de sebep olabilir. Yine de Sontag tedbiri elden bırakmaz, her zaman bir çekincesi vardır.

Gerçek bir vahşet görüntüsüne bakmak şok edici ve utanç vericidir. Ama Sontag'a göre fotoğraftan beklenen şey herhangi bir duygu uyandırması değil, bir şeyi aynen göstermesidir. Fotoğrafların -elle çizilmiş resimlerden farklı olarak- kanıt sayılabilmelerinin nedeni de budur (Sontag, 2004:46). Ama bu şok duygusu birkaç tekrardan sonra azalacaktır, hatta ona göre son yıllarda "kaygı gözeten fotoğrafçılık, bilinci ve vicdanı uyandırdı̆̆ 1 kadar çok onu öldürmeye de katkıda bulunmuştur" (Sontag, 2008:26). Sontag'ın bu vargısına itiraz edilebilir. Elbette fotoğrafın yarattığı "şok" duygusu geçicidir çünkü bu duygu yapısı gereği zaten öyledir. Ancak bazı fotoğraflar bilinci yaralar ve bu kolay kolay etkisini yitirmez. Örneğin; İkinci Dünya Savaşı sonrası açığa çıkan toplama kampı görüntüleri, ya da daha yakın bir tarihe ait olan Ebu Garib cezaevi fotoğrafları birer kanıttır. Butler'ın ifadesiyle bu imgeler kamuoyunu sarsmıştır. Yani fotoğraflar bizim yorum imkânımızı kısıtlamak şöyle dursun, aslında tam tersine bunun önünü açmıştı. Butler'ın Sontag'ın yazılarına getirdiği eleştiri bu manada haklıdır. Dolayısıyla fotoğrafın kendi başına bir yorum sunmadığı, münferit ve anlık imgeyi kısa açıklamalarla ve yazılı analizlerle tamamlamak gerektiği yolundaki yorumu kabul etmek mümkün değildir (Butler, 2015:68). Fotoğrafın kendi gerçekliğinde kamuoyunu etkileme en azından merak uyandırma işlevi malumdur. Üzerinde türlü çeşitli spekülasyon yapılan olayın açığa çıkan fotoğrafı Butler'ın da vurguladığı gibi yazılı açıklamaya bile gerek bırakmayabilir.

Fotoğrafın özellikle savaş ya da vahşeti gösteren fotoğrafın teşhir edici yönü de vardır. Sontag, sakatlanmış, yaralanmış bedenler Asya ya da Afrikalılara aitlerse bunların kolaylıkla teşhir edildiğini sergilendiğini söyler. Ona göre bu gazetecilik adeti, egzotik (yani, sömürgeleştirilmiş) insanları çekinmeden teşhir etmeyi matah belleyen ve kökü yüzyıllara dayalı bir pratiğin mirasıdır: nitekim Afrikalılar ve uzak Asya ülkelerinin sakinleri, on altıncı yüzyıldan yirminci yüzyılın başlarına değin Londra, Paris ve diğer Avrupa başkentlerinde açılan etnolojik sergilerde hayvanat bahçesi hayvanları gibi teşhir edilmişlerdir (Sontag, 2004:72-73). Bir Taliban askeri, Ortadoğu'da vahşice katledilmiş bedenlerin gösterilmesi ve bu şekilde teşhir edilmesi yüzyılların verdiği bir alışkanlıktır. Bu alışkanlıkla fotoğraf sanatının tüketim nesnesi haline de gelebileceği uyarısını birlikte düşünmek gerekir. Sontag'a göre böyle bir dünyada hüzünlü bir sahneyi yansıtan bir fotoğrafın nasıl bir etki yapacağı baştan kesin biçimde öngörülemez. İnsan dış dünyada da korku ve dehşete alışma eğilimdedir ve bunun fotoğrafları da alışabilir. Şok edici, üzücü, sarsıcı şeylere sürekli maruz kalanlar buna alışma eğilimi de gösterebilirler. Tüm bunları birlikte düşündüğümüzde bizi seyirci konumuna getiren bu fotoğraflara dair Sontag şöyle sorular sorar: Peki, bütün bu resimleri sergilemenin yararı nedir? Öfke uyandırmak mı? Kendimizi kötü hissettirmek, yani, üzüntüye ve dehşete boğmak mı? Yas tutmamıza yardımcı olmak mı? Vahşetin bugün cezaland1rılması mümkün olmayan uzak geçmişte kaldığı dikkate alındığında, böyle resimlere bakmak sahiden gerekli midir? Bu resimleri gördüğümüzde daha iyi mi olacağız? Onlar bize gerçekten bir şey öğretirler mi? Zaten bildiğimiz (bilmek istediğimiz) şeyleri doğrulamaktan öte ne anlamları vardir? (Sontag, 2004:92).

Bu soruları Butler'ın özne tasavvurunu dikkate alarak tekrar düşünmek faydalı olabilir. Butler, epistemolojik çerçevenin dışında kalanlar ve yok sayılanlarla bu çerçeveye dâhil edilenleri iki 
Ergün, E. (2016). Gösterilebilir şiddetin gerçekliği. International Journal of Social Sciences and Education Research, 2 (2), 364-373.

kutba ayırır. Ona göre hayattan sayılmayan ya da başından itibaren belirli epistemolojik çerçeveler dâhilinde kavranabilir olmayan hayatlar zaten hiçbir zaman tam anlamıyla yaşanmamış ya da kaybedilmemiştir (Butler, 2015:9). Bunu belirleyen ise iktidar tertipleridir. İktidar, başkalarının hayatını kayıp ya da incinmiş (kaybedilebilir ya da incinebilir) hayatlar olarak kavrıyor ya da kavrayamıyor oluşumuzu belirler (Butler, 2015:9). Diğer bir deyişle bizim beden oluşumuzu, özne olarak kavranmamız bu iktidar çeperinde gerçekleşir. Dolayısıyla özne dahi sayılmayan yığınların vahşet fotoğraflarından üzüntü duyulmaz, bunların teşhir edilmesinden dolayı etik bir kaygı oluşmaz. Onlar zaten iktidar tertipleri uyarınca kadrajda o şekilde sergilenmesi istenenlerdir. Fotoğrafın içerisinde yer alan özneler yası tutulamayanlardır. Bu fotoğrafı sergileyen, çerçeveyi belirleyen için böyle iken o fotoğraflara bakanlar onu görenler için de aynı tepkiye mi sebep olur? Butler'ın, Sontag eleştirisini bu bağlamda değerlendirmek gerekir.

Butler'a göre belirli insan figürlerinin tanınabilirliğini tayin eden çerçevelerin, hangi hayatların yası tutulabilir olduğunu, hangilerinin olmadığını belirleyen daha kapsamlı normlarla ilişkisi düşünülebilir. Başkalarının acısına tepki verip vermediğimizin ve bunu nasıl yaptığımızın, ahlaki eleştirilerimizi formüle etme ve siyasal analizlerimizi ifade etme biçimimizin önceden tesis edilmiş bir algılanabilir gerçeklik alanına bağlı olduğudur. Bu algılanabilir gerçeklik alanında, tanınabilir insan mefhumu, insan olarak adlandırılamayan ya da ele alınamayan şey üzerinden ve ona karşı biçimlendirilerek muhafaza edilir, bu şey, tanınabilir insanı negatif belirleyen ve onu sarsma potansiyeli barındıran bir figürdür (Butler, 2015:65-66). Bu ifade Sontag'ın fotoğrafı çekilebilir kılınan Afrika ve Asya ülke sakinlerini anımsatır. Örneğin işkence edimlerinin fotoğrafının çekilmesi kamusal bir tartışmaya konu edildiğinde, fotoğrafın sahnesi de genişletilmiş olur. Sahne artık hapishanenin uzamı ve sosyal senaryosundan çıkmış, fotoğrafın gösterildiği, görüldüğü, sansürlendiği, halka duyurulduğu, tartışıldığı ve üzerine düşünüldüğü toplumsal alana dönüşmüştür. Yani fotoğraf sahnesinin zaman içinde değişikliğe uğradığı söylenebilir (Butler, 2015:79). Böylece olan biten sadece gösterilenle değil hem fotoğrafın öncesiyle hem de sonrasıyla ilgilidir. Çok daha geniş, çok daha karmaşık bir ağ söz konusudur. Bir katliam fotoğrafı sonrasında olanlar Sontag'ın uyarılarını da akılda tutarak-fotoğrafin nasıl bir bilgi nesnesi olacağını belirler.

Şiddet fotoğraflarına verilen tepkilerin türlü sebepleri olduğu gibi -bir görüşe göre insanların acı çekme ve sakatlanma sahnelerine karşı bir iştahı vardır- kayıtsızlık söz konusu olduğunda da sebepler çeşitlenir. Kimine göre bu fotoğraflara gösterilen tepki savaş ve katliamları durdurmayacaktır. Ya da kimileri bu fotoğraflardan korku duyarlar ve görmezden gelirler. Sontag'a göre insanlar acının peşine daha çok değil, daha az hissetmek için düşerler ( Sontag, 2008:49). Ancak bu fotoğraflara fotoğrafçı ya da izleyici açısından değil de bizzat fotoğrafın kendisinden yola çıkarak düşünmek faydalı olabilir. Butler'ın belirttiği üzere yorum öznel bir edimle sınırlandırılarak kavranamaz. Yorum, söz konusu janrın ve tarzın duygulanımın iletilişine dair yapısal kısıtları sayesinde -ve böylece bazen kişinin isteği hilafına ya da kişiye rağmen-şekillenir. Dolayısıyla sadece fotoğrafçı ve/veya izleyici açıkça yorum yapmaz, fotoğrafın kendisi de izleyiciyi sarsabilir (Butler, 2015:69). Fotoğraflar siyasal alanda Sontag'ın düşündügünün aksine heyecan uyandırabilirler. Hiç beklenmeyen tepkilere yol açabilirler. Vahşetin etik bir değeri vardır. Sontag, "siyasal bilincin varlığı" (Sontag, 2008:23) olmadan bu tür fotoğraflara tepki verilemeyeceğini söylemekte haklıdır. Ancak özne tasarımında siyasal bilincin varlığı düşünülenden çok daha geniş bir alana yayılmıştır. Dolayısıyla kitlesel acılara duyarlı olmak, onlardan ders çıkarmak bir dizi hukuksal ve etik yaptırımlarla birlikte düşülmeyi gerektirir. 
Ergün, E. (2016). The reality of demonstrable violence. International Journal of Social Sciences and Education Research, 2 (2), 364-373.

\section{Sonuç}

Denilebilir ki belgesel fotoğraf eleştirilerinde Sontag'ın haklı olduğu birçok konu olmakla birlikte, fotoğrafın belge niteliğinin olmadığı argümanını kabul etmek mümkün değildir. Unutulmaması gereken şey özellikle savaş suçlarının kanıtlanması için fotoğrafa ihtiyaç duyulduğudur. Aslında Sontag da buna katılır. Ancak o, bir vahşetin vuku bulup bulmadı̆̆ına dair bir yargıya varmanın, sözlü ya da anlatısal bir yorum olduğunu ve bu yorumun iddianın ispatlanması için fotoğrafa başvurduğunu söyleyecektir. Butler'a göre bu, iki nedenden dolayı sorunlu bir yanıttır: Birincisi, fotoğraf kanıtı, dolayısıyla iddianın kendisini oluşturur; ikincisi Sontag, sözlü ya da dilsel olmayan medya biçimlerinin "argümanlarını" oluşturma sürecini yanlış anlamıştır. En saydam belgesel görüntüleri bile çerçevelenmiş, hatta belli bir amaçla çerçevelenmiştir ve o amacı çerçevesinin içinde taşır, onu bu çerçeve aracılığıyla gerçekleştirir. Böyle bir amacın yorumlayıcı olduğunu varsayarsak, fotoğraf da kaydettiği gerçekliği yorumlar gibi görünmektedir ve bu ikili işlevini, yazılı ya da sözlü bir biçimde sunulan bir başka yorum için "kanıt" olarak sunulduğunda da muhafaza eder. Nihayetinde, fotoğraf vahşet edimlerini salt işaret etmekten çok bu edimleri, onların adını koyacak olanlar için tespit ve tasdik eder (Butler, 2015:70-71). Burada önemli olan neyin gösterildiğinden ziyade nasıl gösterildiği meselesidir. Butler'a göre "nasıl” bizim algımızı ve düşüncemizi de hazırlar. Devlet gücü haberci ve kameramanların teyit etmek için orada bulunduğu perspektifi tayin etmeye kalkıştığında, çerçevenin içinde kalan ve onun bir parçası olan eylem de devletin zorla dayattığı savaş yorumunun bir parçası halinde gelir. Fotoğraf sadece yorumlanmayı bekleyen görsel bir imge değildir; kendi başına etken bir biçimde hatta bazen zorla yorumlar (Butler, 2015:72). İşkence fotoğrafları delil olarak kullanılır ve bu bir olguyu tesis eder. Butler'ın ifadesiyle potansiyel ya da fiili hukuki kovuşturmalar çerçevesinde fotoğraf halihazırda yasanın ve hakikatin söylemi içinde çerçevelenmiştir (Butler, 2015:80). Tüm bunlara ek olarak Butler, fotoğrafların ne çerçevelenme şekline ve ne tür bir medya aracılığıyla sunulduğuna göre değişiklik gösteren, birbirinden tamamen farklı amaçlarla araçsallaştırıldığını kabul etmemiz gerektiğini söyler (Butler, 2015:90). Bu bir özne üretimidir. Kültürel formasyonlardan bağımsız düşünülemez. Guantamano mahkûmlarına işkence edenlerin utandırma ve aşağılama çabalarının yanı sıra Arap özneyi ve Arap zihniyetini hedef aldığı düşünülebilir. Bunun gerekçesini kendimize sormamız gerektiğini söyleyen Butler, fotoğrafların delil niteliği tanışmasının içine bunu da dâhil eder.

Fotoğraf, özellikle şiddetin yüzyılı olan yirminci yüzyılda dünyada yaşanan vahşet ve katliamları belgelemiştir. Elbette ki bu, fotoğraftan haberdar olan tüm insanların aynı 1stırabı aynı acıyı hissettiği anlamına gelmiyor. Öyle olsaydı savaşlar ve katliamlar devam ediyor olmazdı. Yine de Linfield'e kulak verilim: "hiç fotoğraf görmemiş olsaydınız, entelektüel, politik ve ahlaki dünyanızın nasıl olabileceğini bir an için düşünün” (Linfield, 2013:60). Hiç fotoğraf görmemiş olsaydık, an'a tanıklık eden fotoğraflardan haberdar olmasaydık kendini sürekli yenileyen ve sürdüren bir şaşkınlık etkisine maruz kalmasaydık kuşkusuz siyasal ve etik dünyamızda oldukça büyük bir boşluk olurdu. Bu manada denilebilir ki belgesel niteliğinde fotoğraf gerçeklik alanının inşasında önemli bir paya sahiptir. Fotoğrafın kurduğu özne sadece onun çerçevesiyle sınırlı olmayıp çok daha geniş bir alanı kuşatır.

\section{Kaynakça}

Barthes, R. (2011). Camera Lucida. Reha Akçakaya (Çev). İstanbul??: 6:45.

Berger, J. (1986). Görme Biçimleri. Yurdanur Salman (Çev). İstanbul: Metis. 
Ergün, E. (2016). Gösterilebilir şiddetin gerçekliği. International Journal of Social Sciences and Education Research, 2 (2), 364-373.

Berger, J. (2014). Görme Duyusu. Osman Akınhay (Çev). Agora Kitaplığı, İstanbul.

Benjamin, W. (2014). Fotoğrafin Küçük Tarihi. Barış Tanyeri (Çev). İstanbul: 6:45.

Butler, J. (2015). Savaş Terapileri. Şeyda Öztürk (Çev). İstanbul: Yapı Kredi.

Linfield, S. (2013). Acımasız Aydınlık. M. Emir Uslu (Çev). İstanbul: Espas.

Slahi, M. O. (2015). Guantanamo Günlüğü. Ali Çakıroğlu (Çev). İstanbul: Belge.

Sontag, S. (2004). Başkalarının Acısına Bakmak. Osman Akınhay (Çev). İstanbul: Agora.

Sontag, S. (2008). Fotoğraf Üzerine. Osman Akınhay (Çev). İstanbul: Agora. 
Ergün, E. (2016). The reality of demonstrable violence. International Journal of Social Sciences and Education Research, 2 (2), 364-373.

\section{Extended abstract in English}

Photograph is one of the primary ones when the icon of the modern era. Photograph which leads to some tensions and conflicts such as its comparison with painting, its rupture and if its an art in its own right, has also a documentary-like nature. This is also a discussion of the nature preserves its currency at least until the others. In the past, photograph spread in time to a unique event of the middle class. In particular, its importance is highly increased when it comes to social events. Visual images almost took the place of real world and the problem if they can be regarded as evidence is got deepen with the expansion of photograph into a very large area.

We want to see the photograph of what we heard or thing that we want to prove the truth. It is important to be deemed registered. We would like to see the photographs that even if the distortion is probable. Sometimes the photographs they see the task of proving the correctness of what is transmitted in writing.

When there is a critique about the photograph which is documentary, Sontag is the first name that comes to mind. For Sontag a gap is opened - who questioned the photograph is a documentary or not- between reality and image, it is no longer closes. According to her photograph just will gain documentary qualification with a description.

There are several reasons why Sontag is -to say the least- cautious about photograph's property of being documentary. The first of these is that photograph changed the idea of reality. Such that we can barely place the photograph just with a subtitle in field of reality. The idea that photograph makes us insensitive which is actually a contemporary cliche is another reason. In fact, the people who are continuously exposed to horrible images, a little while later won't be affected by them. We see the same cliche in the cinema. Modern directors used this a lot. For example, in Haneke's movies, family have their dinner in peace while a television which is working on background with scenes of war and violence. The information of the pain or the violence, it is the figure of the fast flow -as a matter of course- reduces the impact of these images. Storm of horrifying images make insensitive but they still have qualification of documentary.

Another argument of Sontag is the reality that wars are endless and unavoidable. According to him photograph is kind of a rhetoric on its own and it is reproduced by recursion of a phenomenon. It simplifies the phenomenon. However, unlike Sontag, Linfield says that photographs show us our inevitable failure of understanding what is human. In this sense, photograph creates a political awareness besides its documentary characteristic.

Sontag, acknowledged that the photo had made an impression above us with its emphasis on temporariness. According to her, the photo caused "shock" effect and also this effect was not give us opportunity for interpretation. A photo has barely clarified with a description text under it. Thereby the photo's political and ethical meaning was skeptical, its witness was eristic for Sontag. Whereas Butler object to Sontag and acknowledged that the photo -especially war and violence's photos- gives us opportunity to a perceptible reality. According to her, photos could change our world, could be witness and could use to prove war crimes. Butler's critiques on Sontag's writing is right in this sense.

Photograph documented the atrocity and massacres throughout the world in the 20th century which is the century of violence. Of course, this doesn't mean everyone aware of photograph felt the same suffering and pain. If this was the case the wars and massacres wouldn't be going on today. There would be a vast emptiness in our political and ethical world if we have never seen a 
Ergün, E. (2016). Gösterilebilir şiddetin gerçekliği. International Journal of Social Sciences and Education Research, 2 (2), 364-373.

photograph and weren't aware of photographs that show that split second and weren't exposed over an over to a recursive effect of consternation. In this sense, we may say photograph has an important role of creating the field of reality. The object which photograph creates is not limited with its environment and surrounds a much larger area.

This paper is an attempt to critical based on the critics of Sontag's about photo and about these kinds of photo's meaning. The demonstrability has semtinized within the frame of such questions "What does a photo tell us? How could the photo's fictional world reflect the reality? Could a photo change boundaries of the relation between fiction and reality?" 